\title{
THE INTERNAL HETEROGENEITY OF INDUSTRIAL DISTRICTS IN ITALY, BRAZIL AND MEXICO
}

\author{
Roberta Rabellotti* \\ and Hubert Schmitz**
}

IDS Working Paper 59

\begin{abstract}
Summary
Industrial districts have attracted the attention of development economists in search for new models of industrial development. Many case studies have shown that clustering helps local enterprises to overcome growth constraints and compete in distant markets. However, empirical studies also reveal shortcomings of the industrial district model. This paper shows that within the districts there is enormous heterogeneity by size and performance. Even though clustering firms feed on each other, they vary a great deal in the strategies they employ and the growth they achieve. This internal heterogeneity is investigated for three cases: the shoe industries in Italy, Brazil and Mexico.
\end{abstract}

Department of Economics, Via del Santo n 33, University of Padua, 35123 Padua, Italy. Email: rabellotti@decon.unipd.it

** Institute of Development Studies, University of Sussex, Brighton BN1 9RE, England. Email: h.schmitz@sussex.ac.uk 


\section{INTRODUCTION $^{1}$}

Over recent years a good deal of case material has emerged on industrial districts in advanced and less developed countries. While the growth record has varied between districts and over time, it is recognized that clustering has helped local enterprises to overcome growth constraints and compete in distant markets. In our own work we have used the notion of collective efficiency to explain such ability to grow and compete. The empirical underpinning came from footwear districts in Italy, Brazil and Mexico (Rabellotti 1997a, Schmitz 1995b). In this paper we will look inside those districts and show that behind this collective efficiency there is enormous heterogeneity. Even though clustering firms feed on each other, they vary a great deal in the strategies they employ and the growth they achieve.

While the internal heterogeneity is not a new discovery (see, for example, Knorringa, 1996 and Nadvi, 1996), it deserves more attention. Laying the internal unevenness bare is important because the distant observer often assumes a homogeneity and unity which rarely exists. The notion of collective efficiency may have inadvertently contributed to this view. As expressed in an earlier paper, "even where a collective capacity to compete, adapt and innovate has emerged, it is important not to expect an island of unity and solidarity. Collective efficiency is the outcome of an internal process in which some enterprises grow and others decline." (Schmitz 1992:65).

This paper takes a more systematic view of heterogeneity inside the districts. It does so for three cases: the shoe industries of Italy, Brazil and Mexico. Data on these cases was collected using a combination of quantitative and qualitative research: a survey questionnaire (covering around 50 enterprises per district) and structured interviews with manufacturers and 'key informants'. The evidence on heterogeneity comes primarily from our surveys and is presented in section 3. The qualitative information is used for interpreting the findings as well as for the brief overview of the districts which is given in section 2 .

\section{SHOE DISTRICTS IN ITALY, BRAZIL AND MEXICO}

The enormous internal heterogeneity shown later in this paper took us by surprise. It was a byproduct of research which sought to address a different question: to what extent does the industrial district model capture the reality of footwear agglomerations in Italy, Brazil and Mexico? The four main features of this model are (Rabellotti 1995):

- spatial and sectoral concentration of enterprises;

- socio-cultural ties amongst local economic agents, creating a common code of behaviour;

- intense vertical and horizontal linkages, based both on market and non-market exchanges of goods, services, information and people; 
- a network of public and private local institutions supporting the enterprises in the district.

The above features help local firms to attain collective efficiency which we define as the comparative advantage derived from local external economies and joint action (Schmitz 1995). This section shows in a summary fashion to what extent the districts in Italy, Brazil and Mexico live up to the text model. It is preceded by a brief overview of their growth record since the 1960s. The purpose of this section is thus merely contextual. It provides the setting for the subsequent analysis which focuses on the internal heterogeneity in the aforementioned districts.

\subsection{Italy}

The recent history of the Italian footwear industry can be divided into three main periods: a first long period of continuous expansion from the beginning of the 1960s until 1985, a second period of crisis and restructuring of the sector until 1992 and a third period of recovery corresponding with the devaluation of the Lira.

The outstanding growth of the Italian footwear industry was export-led: at the beginning of the 1950s exports represented a mere 3.7 per cent of the total production, by 1970 the proportion of exports had increased to 63 per cent, in 1985 it was 83 per cent and in 199584 per cent (ANCI, 1996).

During the 1980s, other European countries like Spain, Portugal, some south-east Asian NICs like Taiwan and South Korea and also some developing countries like Brazil and China became very competitive in the international market and greatly increased their exports. Especially the latter could exploit a labor cost advantage with respect to Italy. Continuous upgrading of quality and the recent Lira devaluation helped the Italian footwear industry to regain some lost competitiveness.

Striking features of the Italian shoe sector are the high number of producers, the small average firm size and the spatial concentration in a few specialized areas. In 1995 the total number of producers was 8,597 and the total industry workforce was 120,358 (ANCI, 1996). Feeding into the shoe sector were 2,265 producers of components and accessories, 2,400 tanneries and 400 producers of specialized machinery (ANAC 1996, UNIC 1996, ASSOMAC,1996).

Particularly noteworthy is the size distribution of shoe firms. Only 0.7 per cent of firms have more than 100 employees and firms with a workforce of less than 50 employees account for 74.8 per cent of all employment; among them there is a considerable number of firms employing fewer than 10 people, representing 72 per cent of all firms in the sector and 23 per cent of all employees (Gaibisso, 1992).

The sector is geographically concentrated in a few areas comprising mainly small towns and villages. The two footwear districts selected for our empirical survey are Marche and 
Brenta, both containing a large concentration of firms specializing in the production of high and medium quality shoes, with very strong export orientation.

\subsection{Brazil}

The Brazilian case focuses on the Sinos Valley located in the state of Rio Grande do Sul. Shoe manufacturing in the Sinos Valley developed over two and a half decades from an agglomeration of small enterprises producing only for the internal market to a district with enterprises of all sizes exporting around 70 per cent of their output (Schmitz, 1995a). Their growth and competitiveness cannot be understood by analyzing enterprises individually. The 500 shoe manufacturers draw on over 1,000 suppliers of specialized inputs and services and on a range of self-help institutions. However, there is not just complementarity and cooperation but also fierce local rivalry confirming that the two do not exclude each other. The Sinos Valley is not the only shoe producing district in Brazil but it is largely responsible for the country's export performance. Between 1970 and 1990, Brazil raised its share of world exports in leather shoes from 0.5 to 12.3 per cent.

Three growth periods can be distinguished for the case of the Sinos Valley: during the 1950s and 1960s growth of the local sector was achieved by increasing its reach from the regional market to the national market. The 1970s and 1980s was a period of rapid export-led growth. While the previous period saw a rapid increase in the number of shoe producers, the export boom led to a size increase of existing enterprises.

The 1990s has been a period of slower and fluctuating growth. The industry has had to restructure in response to two pressures: China has squeezed Brazil out of its main market segment of cheap, standardized leather shoes, particularly in the US market. Brazil was forced to move up market and raise quality. The 'Chinese squeeze' coincided with the 'discovery of inventory cost' on the part of overseas and national retailers. Instead of keeping large stocks in their workhouses, buyers now place small orders which are then repeated in line with sales. Manufacturers have reduced the time between order and delivery to a third or a quarter of what it used to. This pressure to produce better, faster and in small batches has led to a restructuring giving more scope to small enterprises and making large enterprises reorganize internally into mini factories. This has occurred in a process of wildly fluctuating growth due to under- and then over-valuation of the Brazilian currency.

\subsection{Mexico}

Mexico was a strongly protected market before trade liberalization began in 1988. The opening up of the Mexican market to international competition, through the elimination of import licensing and tariff reduction, had a big impact on the footwear industry. The market was flooded with imports which increased from US\$ 13.7 million in 1987 to US\$ 145.2 million in 
1994. More recently, a series of events, namely the 1994 Peso devaluation and the 1993 and 95 rise in shoe tariffs, represented positive shocks for the domestic producers and marked the beginning of a recovery for the Mexican shoe industry (Rabellotti, 1997b).

The sector is composed of 2,300-odd enterprises; 96 per cent of them employ less than 100 people, 3 per cent between 100 and 250 people and only 1 per cent more than 251 . From the geographical point of view, the bulk of the shoe industry is concentrated in three areas: 39 per cent of the firms are in Leon, 33 per cent in Mexico State and the capital and 14 per cent in Guadalajara (CANAICAL, 1995). Our research has focused on Leon and Guadalajara. Both have a long tradition in the shoe sector and a clear product specialization: Guadalajara concentrates on women's and Leon on men's shoes.

A difference between the two districts is that in Leon the local economy is dominated by the shoe sector, with more than 40 per cent of the industrial workforce employed in shoe or related industries, while in Guadalajara the industrial structure is much more diversified. Nonetheless, both in Guadalajara and Leon there is a critical mass of firms specialized in the shoe filière.

\subsection{Overview}

Table 1 gives an overview of the numbers of shoe firms, suppliers and workers in the districts examined in the three countries. It shows that, in all three cases, there is a formidable spatial and sectoral concentration of enterprises. While the data are not strictly comparable, we can conclude that in the Brazilian case the average size of enterprise is higher than in the Mexican and the Italian cases.

Table 1: Shoe districts in Italy, Mexico and Brazil (number of firms and workers)

\begin{tabular}{|l|c|c|c|c|}
\hline & $\mathrm{N}^{\circ}$ of shoe firms & Direct jobs & $\mathrm{N}^{\circ}$ of suppliers & Direct Jobs \\
\hline $\begin{array}{l}\text { Brenta and Marche (1), } \\
\text { Italy }\end{array}$ & 2,864 & 40,039 & 1,145 & 11,748 \\
\hline $\begin{array}{l}\text { Guadalajara and Leon } \\
\text { (2), Mexico }\end{array}$ & 1,238 & 67,594 & 920 & n.a. \\
\hline $\begin{array}{l}\text { Sinos Valley (3), } \\
\text { Brazil }\end{array}$ & 480 & 70,000 & 1,139 & 73,500 \\
\hline
\end{tabular}

(1) 1994 - Source: ANCI, 1995

(2) 1994 - Source: Camara de la Industria del Calzado, 1995

- Shoe firms are only the members of the Camara.

- Data on suppliers are only for Leon. Data for Guadalajara are not available.

(3) 1991 - Source : ABAEX, 1992

- The figure for shoe firms does not include 710 small subcontractors (included under suppliers).

- Suppliers in Sinos Valley have clients in other parts of Brazil. 
In our previous work we have assessed the correspondence of the case studies with the industrial district model set out above. The results of our investigation are summarized in Table 2. Clearly, such a mapping exercise has its weaknesses because much of the rich detail of the case studies is lost when each characteristic is reduced to being either 'strong', 'medium' or 'weak'. Nevertheless, the exercise has its merits for comparative analysis and allows us briefly to present some of the main findings of our previous work.

Table 2: Mapping of shoe clusters

\begin{tabular}{|l|c|c|c|}
\hline & Italy & Mexico & Brazil \\
\hline $\begin{array}{l}\text { Geographical and sectoral } \\
\text { concentration }\end{array}$ & STRONG & STRONG & STRONG \\
\hline Socio-cultural milieu & STRONG & MEDIUM & $\begin{array}{c}\text { FIRST STRONG } \\
\text { THEN WEAK }\end{array}$ \\
\hline Backward linkages & STRONG & WEAK & STRONG \\
\hline Forward linkages & MEDIUM & WEAK & MEDIUM \\
\hline $\begin{array}{l}\text { Horizontal inter-firm } \\
\text { relationships }\end{array}$ & STRONG & MEDIUM & MEDIUM \\
\hline Business associations & STRONG & MEDIUM & STRONG \\
\hline Government support & WEAK & WEAK & WEAK \\
\hline
\end{tabular}

The existence of a critical mass of spatially concentrated and sectorally specialized enterprises was a criterion for selecting the research areas and is therefore a strong feature of each district under investigation. As regards the other characteristics, they are strong in the Italian districts except for two unexpected results: forward linkages are not strong because Italian shoe enterprises for a long time did not care much about marketing; Italian footwear entrepreneurs concentrated their efforts on quality and fashion without much attention to brand names and marketing channels. Government support was weak; business associations played a greater role than government policies aimed at supporting the industry.

Moving to Mexico, the main point to stress is the weakness of backward linkages. In other words, the division of labor is comparatively low and this has two causes: first of all, the protection of the domestic market has for a long time limited competition and the incentive to specialize; secondly, the sector lacks a standard technical language and a commonly accepted measurement system. In contrast, the Brazilian case has a much deeper division of labor. As mentioned before, Brazil has more large enterprises than Italy or Mexico, but the enterprises which are large today were small two or three decades ago. Even though their growth has been 
export led, they have little control over their forward linkages because of under-investment in brand names and marketing channels.

From the above summary of some of the main findings of our previous work it is evident that one needs to go beyond the model to understand the case studies analyzed. The investigation of their internal heterogeneity, carried out in the rest of the paper, seeks to overcome one of the main shortcomings of the industrial district model.

\section{INTERNAL HETEROGENEITY}

An unexpected result brought out by our fieldwork was the existence of large internal differences in the districts investigated. Indeed, our research strategy and questions were not tailored to investigating this issue. Nevertheless, the results are sufficiently clear to deserve attention.

To investigate this heterogeneity among enterprises belonging to the same district, we conducted a statistical analysis, based on two exploratory multivariate techniques: factor and cluster analysis. These techniques were used to examine a set of variables selected from the sample surveys ${ }^{2}$. These variables represent features like firm size, performance, degree of technological innovativeness, market segment, marketing strategy, links with other local firms, use of entrepreneurial associations (detailed in Appendix).

Factor analysis has the primary objective of simplifying the description of the economic systems analyzed in Brazil, Italy and Mexico. It identifies a relatively small number of underlying principal elements or 'factors' that explain the correlations among a set of variables; in other words, it summarizes a large number of variables and translates them into a smaller number of 'derived' variables or 'factors'. The comparison of the principal factors extracted from the three samples allows some interesting considerations presented below.

Furthermore, factor analysis is used to run a multivariate cluster ${ }^{3}$ analysis, based on the factors identified, instead of the original variables. Cluster analysis groups firms according to their degree of vicinity in respect to the main underlying factors which characterize the economic structures of the samples. If such clusters emerge, with significant differences between the groups, the hypothesis of heterogeneous behaviour of firms within the districts is supported.

The main results of these statistical exercises are presented in the remainder of this section, while the concluding section puts forward some further considerations on heterogeneity, drawing also on qualitative insights.

\subsection{A comparison of the underlying principal factors}

Many variables can be used to describe the economic systems analyzed in Italy, Brazil and Mexico; however, the description might be greatly simplified if it were possible to identify a 
few underlying elements or factors. A principal factor summarizes sets of closely related variables; in essence, it is a concise summary variable, embodying all the original variables and explaining the sample variability as much as possible ${ }^{4}$. The advantage of principal factors is that by using just a few of them (three in our analysis) we can explain a large share of the total sample variance (in our analysis 87 per cent in Italy, 62 per cent in Brazil and 76 per cent in Mexico), taking into account all the original variables. At the same time within each factor, variables are classified according to their importance in the overall variation (Kim and Mueller, 1978).

From a statistical point of view, the results obtained with factor analysis on the Italian, Brazilian and Mexican samples are satisfying because the total explained variability is very high with only three factors (as mentioned before, 87 per cent in Italy, 62 per cent in Brazil and 76 per cent in Mexico) and furthermore the factors are meaningful, being composed of variables which express similar economic content. (By way of illustration, the first factor in Mexico and the second one in Italy are mainly characterized by variables related to the size of firms and therefore they can be interpreted as concise size indicators). In what follows, we present first the principal factors extracted from the three samples and then compare them.

In Tables 3 and 4 the three principal factors extracted from the Italian sample are presented; for their interpretation the variables appearing in each factor with the highest factor loadings are taken into account ${ }^{5}$. The first factor explains 33 per cent of the total sample variance and characterizes expanding firms, being composed by variables like increasing employment (B612 with a factor loading of 0.57), investments in technology (M11: 0.41), a mixed strategy of commercialization (G142: 0.38 ) and a tendency to own equity shares in other local firms (H21: 0.30). These firms have some difficulties in finding skilled labor (B1012: $0.30)$. 
Table 3: Rotated Factor Matrix*- Italy

\begin{tabular}{|c|c|c|c|}
\hline Variables & Factor 1 & Factor 2 & Factor 3 \\
\hline B612 & 0.57 & 0.06 & -0.23 \\
\hline M11 & 0.41 & 0.40 & 0.03 \\
\hline G142 & 0.38 & 0.06 & 0.17 \\
\hline B1012 & -0.30 & -0.20 & -0.15 \\
\hline $\mathrm{H} 21$ & 0.30 & 0.11 & -0.05 \\
\hline B1 & 0.11 & 0.45 & -0.26 \\
\hline $\mathrm{L} 21$ & 0.28 & -0.44 & -0.07 \\
\hline B25 & 0.06 & 0.42 & 0.05 \\
\hline F112 & 0.33 & 0.42 & 0.28 \\
\hline M18 & -0.25 & 0.39 & -0.12 \\
\hline G31 & 0.32 & -0.38 & 0.15 \\
\hline $\mathrm{H} 41$ & 0.02 & 0.08 & 0.47 \\
\hline H612 & -0.14 & -0.02 & 0.46 \\
\hline D3 & -0.34 & 0.02 & 0.39 \\
\hline M15 & 0.24 & -0.26 & -0.31 \\
\hline Explained Variability & $33 \%$ & $30 \%$ & $24 \%$ \\
\hline
\end{tabular}

* see note 4

Table 4: The principal factors - Italy

\begin{tabular}{|l|l|l|}
\hline \multicolumn{1}{|c|}{ Factor 1 } & \multicolumn{1}{|c|}{ Factor 2 } & \multicolumn{1}{|c|}{ Factor 3 } \\
\hline B612 trend of employment & B1 number of employees & $\begin{array}{l}\text { H41 non-equity agreements with } \\
\text { other local firms }\end{array}$ \\
\hline M11 investments in technology & $\begin{array}{l}\text { L21(-) use of the services of the } \\
\text { entrepreneurial association }\end{array}$ & $\begin{array}{l}\text { H612 informal relationships } \\
\text { within the district }\end{array}$ \\
\hline $\begin{array}{l}\text { G142 forms of } \\
\text { commercialization other than } \\
\text { sale representatives }\end{array}$ & B25\% of exported sales \\
\hline $\begin{array}{l}\text { B1012(-)* availability of skilled } \\
\text { labor force }\end{array}$ & F112 technological level & $\begin{array}{l}\text { D3 \% of upper stitching put out } \\
\text { to other enterprises }\end{array}$ \\
\hline $\begin{array}{l}\text { H21 equity shares in other shoe } \\
\text { firms or in other firms connected } \\
\text { with the sector, located within } \\
\text { the cluster }\end{array}$ & M18 investments in other sectors & $\begin{array}{l}\text { M15(-) investments in } \\
\text { commercialization }\end{array}$ \\
\hline & G31(-) segment of market & \\
\hline
\end{tabular}

* The minus sign means that the correlation with the other variables is negative 
The second factor ( 30 per cent of sample variance) can be interpreted as a size factor: firms of large size (B1: 0.45), exporting a product of low quality (B25: 0.42 and G31: -0.38 ) and producing with advanced technological processes (F112: 0.42). These firms seem to be rather separate from the district and indifferent to its collective effects, as indicated by the diversification of their investments towards other sectors (M18: 0.39) and the scarce use of the services supplied by the entrepreneurial association (L21: -0.44).

Finally, the third factor ( 24 per cent of sample variance) stresses the importance of the collective dimension of the system: high decentralization of the production process (D3: 0.39) and frequent cooperation based both on formal and informal contacts with other economic actors within the district (H41: 0.47 and H612: 0.46).

Concisely, the three main elements of the Italian production systems, identified with factor analysis, are in order of importance: expansion, size and collective efficiency.

Moving on to the Brazilian district (Table 5 and 6), the first factor explains 33 per cent of the total sample variance and is composed by a bunch of variables related to the collective dimension of the district, stressing the importance of horizontal cooperation through institutions (Q161A: 0.62 and Q161B: 0.68) and vertical cooperation with suppliers (Q92A: 0.78). The number of employees appears in the same factor (Q31: 0.60) suggesting a positive correlation between firm size and the indicators of collective efficiency. Moreover, the firm size can help to explain the low percentage of upper stitching put out to other enterprises (Q71H1: -0.67) and therefore the tendency to vertical integration.

Table 5: Rotated Factor Matrix * - Brazil

\begin{tabular}{|l|c|c|c|}
\hline \multicolumn{1}{|c|}{ Variables } & Factor 1 & Factor 2 & Factor 3 \\
\hline Q92A & & & -0.17 \\
Q161B & 0.78 & -0.19 & -0.06 \\
Q71H1 & 0.68 & 0.43 & 0.09 \\
Q161A & -0.67 & 0.24 & -0.28 \\
Q31 & 0.62 & 0.27 & -0.37 \\
& 0.60 & 0.26 & \\
Q101C & -0.09 & -0.90 & 0.19 \\
Q53A & 0.06 & 0.89 & -0.17 \\
Q73C & -0.28 & -0.48 & -0.01 \\
& & & 0.78 \\
Q51B & 0.20 & -0.26 & 0.76 \\
Q21 & -0.17 & -0.06 & 0.73 \\
Q611A1 & 0.19 & 0.03 & \\
\cline { 2 - 3 } & & & $13 \%$ \\
Explained Variability & $33 \%$ & $16 \%$ & \\
* see note 4 & &
\end{tabular}


The second factor explains 16 per cent of the total sample variance and is composed of three variables: percentage of exports (Q53A: 0.89), sales through an independent sale representative (Q101C: -0.90) and assistance provided by subcontractors (Q73C: -0.48). Exportoriented firms do not receive assistance from their subcontractors and do not employ sale representatives to sell their product, as they are more likely to sell through export agents.

Table 6: The principal factors - Brazil

\begin{tabular}{|c|c|c|}
\hline Factor 1 & Factor 2 & Factor 3 \\
\hline $\begin{array}{l}\text { Q92A suppliers offer assistance } \\
\text { with problems arising from } \\
\text { products }\end{array}$ & $\begin{array}{l}\text { Q101C (-)* sales through an } \\
\text { independent sale representative }\end{array}$ & Q51B trend of production \\
\hline $\begin{array}{l}\text { Q161B contacts with the } \\
\text { technology center }\end{array}$ & Q53A \% of exported sales & $\begin{array}{l}\text { Q21 year in which the firm was } \\
\text { established }\end{array}$ \\
\hline $\begin{array}{l}\text { Q71H1 (-) \% of upper stitching } \\
\text { put out to other enterprises }\end{array}$ & $\begin{array}{l}\text { Q73C (-) subcontractors lend } \\
\text { machines }\end{array}$ & $\begin{array}{l}\text { Q611A1 investments in } \\
\text { capacity expansion within the } \\
\text { Sinos Valley }\end{array}$ \\
\hline $\begin{array}{l}\text { Q161A contacts with the training } \\
\text { center }\end{array}$ & & \\
\hline Q31 number of employees & & \\
\hline
\end{tabular}

* The minus sign means that the correlation with the other variables is negative

Finally, the third factor explains 13 per cent of the total sample variance and is also composed of three variables: trend of production (Q51B: 0.78), the year in which the firm was established (Q21: 0.76) and the investments in capacity expansion within the Sinos Valley (Q611A1: 0.73). Older firms are more likely to have registered an increased trend of production and to invest in capacity expansion within the Sinos Valley.

To summarize, we can label the first factor as a collective efficiency component, the second one as an export component and the third as a performance component.

Presenting finally the results of factor analysis for the Mexican sample, three factors explain 76 per cent of the total sample variance (Table 7 and 8). The first factor (39 per cent of the total sample variance) is dominated by the size of firms (B1: 0.64). Other variables, representing the strategies of investments (H57: 0.63, H55: 0.47 and H56: 0.46), the technological level (C3512: 0.46), the quality of product (H7A: 0.57) and the frequency of informal relationships (G1: 0.32) together with the limited importance attributed to institutional assistance (H78: -0.51) are correlated with size. This factor can be interpreted as a confirmation 
of the importance of size and the indifference of large firms to institutionalized cooperation, as in the Italian sample. Nevertheless, in Mexico large firms have frequent informal contacts with other firms within the district.

Table 7: Rotated Factor Matrix * - Mexico

\begin{tabular}{|c|c|c|c|}
\hline Variables & Factor 1 & Factor 2 & Factor 3 \\
\hline B1 & 0.64 & -0.33 & 0.09 \\
\hline H57 & 0.63 & 0.11 & 0.13 \\
\hline $\mathrm{H} 7 \mathrm{~A}$ & 0.57 & 0.06 & -0.19 \\
\hline $\mathrm{H} 78$ & -0.51 & 0.29 & 0.19 \\
\hline H55 & 0.47 & 0.27 & 0.14 \\
\hline H56 & 0.46 & 0.31 & 0.02 \\
\hline G1 & 0.32 & 0.24 & 0.03 \\
\hline F1 & 0.38 & -0.57 & 0.21 \\
\hline D7812 & 0.18 & 0.54 & -0.04 \\
\hline DIII1 & 0.33 & 0.39 & 0.06 \\
\hline D16 & -0.01 & 0.31 & -0.30 \\
\hline G131 & 0.01 & 0.15 & 0.49 \\
\hline $\mathrm{C} 3512$ & 0.46 & -0.05 & 0.46 \\
\hline H76 & -0.22 & 0.24 & 0.37 \\
\hline Explained Variability & $39 \%$ & $22 \%$ & $15 \%$ \\
\hline
\end{tabular}

The second factor explains 22 per cent of the total sample variance and is characterized by variables representing the quality of products (DIII1: 0.39), the design originality (D7812: 0.54) and the commercialization through agents (D16: 0.31), negatively correlated with equity investments in other local firms (F1: -0.57).

Finally, the third factor accounts for 15 per cent of the total sample variance. In this last factor, two variables related to the spatial environment (G131: 0.49 and H76: 0.37) are identified together with a good technological level (C3512: 0.46). The factor can therefore be interpreted as the collective dimension of the analyzed systems, emphasizing the role of supporting institutions and information access. 
Table 8: The principal factors - Mexico

\begin{tabular}{|l|l|l|}
\hline \multicolumn{1}{|c|}{ Factor 1 } & \multicolumn{1}{|c|}{ Factor 2 } & \multicolumn{1}{c|}{ Factor 3 } \\
\hline B1 number of employees & F1 (-) equity shares in local firms & $\begin{array}{l}\text { G131 use of more than one service } \\
\text { of the entrepreneurial association }\end{array}$ \\
\hline $\begin{array}{l}\text { H57 investments in managerial } \\
\text { training }\end{array}$ & D7812 original design & $\begin{array}{l}\text { C3512 good or very good } \\
\text { technological level }\end{array}$ \\
\hline $\begin{array}{l}\text { H7A product quality as a } \\
\text { competitive advantage of the } \\
\text { firm }\end{array}$ & DIII1 high segment of market & $\begin{array}{l}\text { H76 access to information as a } \\
\text { competitive advantage of the firm. }\end{array}$ \\
\hline $\begin{array}{l}\text { H78(-)* institutional assistance } \\
\text { as a competitive advantage of the } \\
\text { firm }\end{array}$ & $\begin{array}{l}\text { D16 \% of products sold by } \\
\text { agents }\end{array}$ & \\
\hline $\begin{array}{l}\text { H55 investments in } \\
\text { commercialization }\end{array}$ & & \\
\hline $\begin{array}{l}\text { H56 investments in technical } \\
\text { training }\end{array}$ & & \\
\hline $\begin{array}{l}\text { G1 frequent informal } \\
\text { relationships within the cluster }\end{array}$ & & \\
\hline $\begin{array}{l}\text { C3512 good or very good } \\
\text { technological level }\end{array}$ & & \\
\hline
\end{tabular}

* The minus sign means that the correlation with the other variables is negative

Thus, the three main elements of the Mexican production systems, identified with factor analysis, are, in order of importance: size, product quality and collective efficiency.

Moving then to the comparison of findings, the most important issue to emphasize is the relevance of the collective dimension in all three samples and especially in the Brazilian district where it comes out as the first, most important factor. This is a very encouraging result because it confirms the importance of the local environment, of the enterprises' embeddedness in their local area and of collective efficiency in all the districts under investigation. However, a different correlation of collective efficiency with firm size seems to exist between the Brazilian district on one side and the Italian and Mexican districts on the other. Both in Italy and Mexico, large firms seem to be rather aside from the rest of the district (B1 in Factor 2 in Italy and in Factor 1 in Mexico), in other words to some extent indifferent to collective efficiency; while in Brazil, as seen above, there is a positive correlation between firm size and the collective component of the district (Q31 in Factor 1).

As regards large Brazilian firms, we can say that - historically speaking - they are all locally embedded in that they have grown from small local firms to large sized firms by drawing 
on and contributing to the district. However, once large size was achieved they split into two categories. One group of firms became very large, integrated vertically and sought independence of the district. These firms are not represented in the sample. The other group which includes more firms (which are not quite as large) continues to draw on and contribute actively to the district. This group is represented in the sample.

The next section seeks to identify more sharply the different groups of firms within the Italian, Brazilian and Mexican districts.

\subsection{Identifying homogeneous groups of firms}

The next logical step after factor analysis from a statistical standpoint is cluster analysis, which aims at constructing homogeneous groups of firms in terms of the variables considered. Clusters of firms are formed on the basis of the principal factors identified in section 3.1, with the aim of identifying the structural characteristics shared by each group (Everitt, 1983) ${ }^{6}$. The identification of clusters of enterprises, characterized by significant differences relative to the principal factors and by their structural features is a confirmation of the hypothesis of heterogeneity among firms within the districts. The remainder of this section shows which clusters were found.

From the Italian sample 5 clusters were identified in terms of the first and the third factor ${ }^{7}$. Remembering that the first factor can be identified as an indicator of performance, characterizing firms with increasing employment and the third factor as an indicator of collective efficiency, the 5 Italian clusters are represented in Figure 1. Table 9 classifies the 5 clusters according to the two factors, as pictured in Figure 1, and the average size of the firms belonging to them. 
Table 9: The Italian clusters

\begin{tabular}{|l|c|c|c|}
\hline & $\begin{array}{c}\text { Performance } \\
\text { (Factor 1) }\end{array}$ & $\begin{array}{c}\text { Collective efficiency } \\
\text { (Factor 3) }\end{array}$ & Size \\
\hline A (8 firms) & good & good & medium \\
\hline B (9 firms) & mixed & very good & small \\
\hline C (8 firms) & mixed & very low & medium \\
\hline D (22 firms) & bad & low & mixed \\
\hline E (3 firms) & bad & low & \\
\hline
\end{tabular}

Table 10: The Brazilian clusters

\begin{tabular}{|l|c|c|c|}
\hline & $\begin{array}{c}\text { Performance } \\
\text { (Factor 3) }\end{array}$ & $\begin{array}{c}\text { Collective efficiency } \\
\text { (Factor 1) }\end{array}$ & Size \\
\hline A (9 firms) & bad & very low & medium to small \\
\hline B (1 firm) & bad & very low & medium \\
\hline C $(2$ firms) & mixed & good & large \\
\hline D $(13$ firms $)$ & mixed & good & very large \\
\hline E $(12$ firms $)$ & good & good & medium \\
\hline F (13 firms) & good & low & small \\
\hline
\end{tabular}

Table 11: The Mexican clusters

\begin{tabular}{|l|c|c|c|}
\hline & Performance & $\begin{array}{c}\text { Collective efficiency } \\
\text { (Factor 3) }\end{array}$ & $\begin{array}{c}\text { Size } \\
\text { (Factor 1) }\end{array}$ \\
\hline A (2 firms) & mixed & medium & large \\
\hline B (10 firms) & bad & medium & medium \\
\hline C (10 firms) & good & good & medium to large \\
\hline D (13 firms) & bad & low & medium to small \\
\hline E (14 firms) & good or stable & good & mixed \\
\hline F (2 firms) & good & & \\
\hline
\end{tabular}



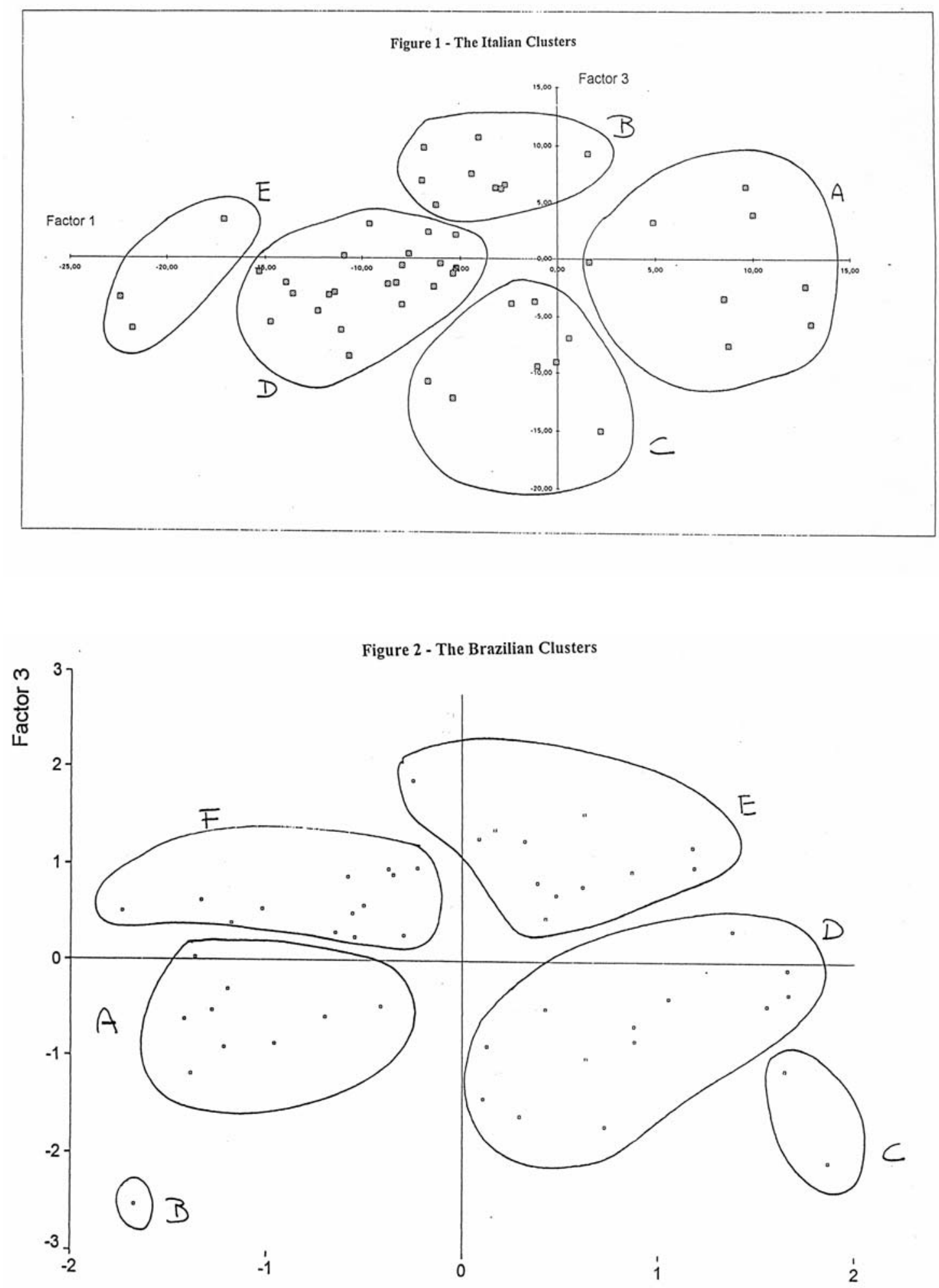

Factor 1 


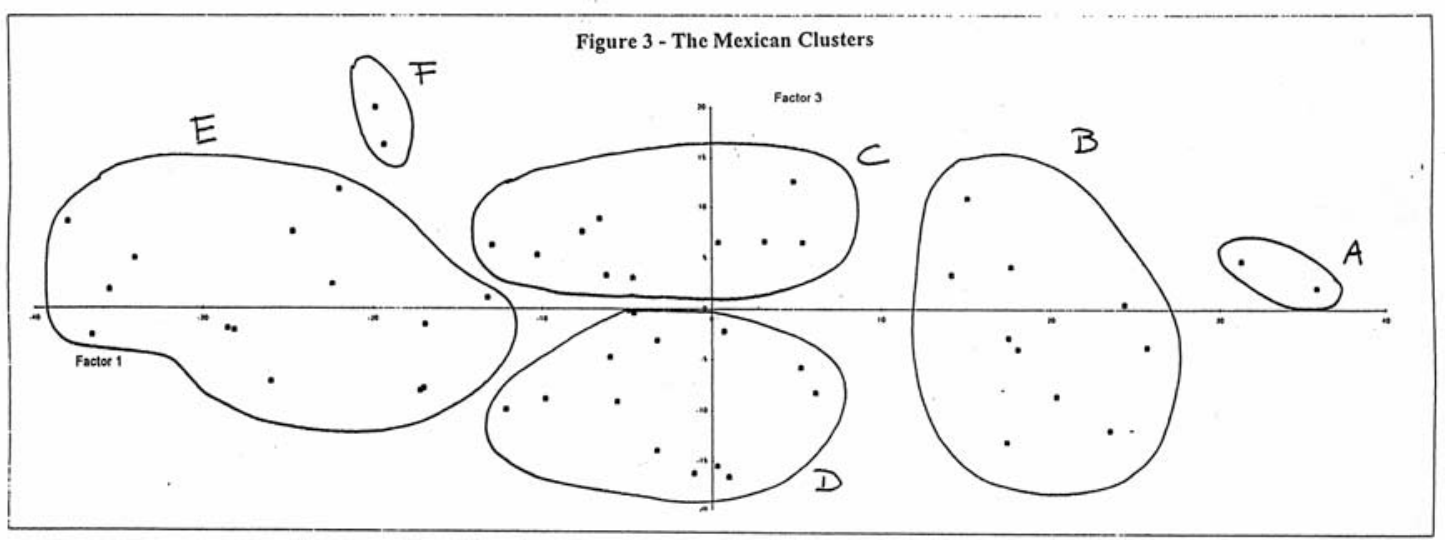

Moving on to the Brazilian sample, 6 clusters were identified in terms of the first and the third factor, namely collective efficiency and performance. The clusters ${ }^{8}$ are shown in Figure 2 and their characteristics are described in Table 10.

Finally in the Mexican sample, the first factor can be interpreted as an indicator of the importance of size, correlated with the investment strategies and the technological level and the third one as an indicator of the collective efficiency. In Figure 3 we have identified 6 clusters and their characteristics are specified in Table 11.

Cluster analysis has made it possible to define several clusters in which the sample firms differ in terms of the main underlying factors, representing the overall variability of a large number of variables selected from our empirical work. In other words, a cluster is composed by firms characterized by homogeneous behaviour concerning the principal factors and often by some common structural features. The first result is therefore that the large majority of the firms in the three samples is distributed into different clusters and there are only very few outliers (clusters B and C in Brazil, cluster E in Italy and clusters A and F in Mexico).

The second result is the homogeneity of firms in terms of size within each cluster; this means that firms of similar size have similar behaviours and structural characteristics. By implication, size differentiation within the same cluster corresponds to differences in conduct and structure. Going a step further, we have found that firms belonging to a specific cluster also share a common behaviour in terms of variables like export-orientation, strategy of putting out some phases of production, investment strategy, technological level or quality of product and these behaviours change among clusters. This heterogeneity among different groups of firms has been usually disregarded in most of the literature on industrial districts, traditionally described as populated by a crowd of small, very similar enterprises ${ }^{10}$.

In addition to these more robust results of cluster analyses, one can derive some tentative conclusions about the existence of an empirical regularity concerning the relationship between performance and collective efficiency. The hypothesis ${ }^{11}$ we would like to advance is that collective efficiency is positively related with performance. This relationship is confirmed in 
several of the clusters identified: A and E in Brazil, A and D in Italy and C and D in Mexico. Excluding outliers, if we analyze the rest of the clusters, that is, D in Brazil and C and B in Italy, the relationship is not clear because the performance is mixed; also in the Mexican clusters B and $\mathrm{E}$ there is not a clear relationship. Only in one cluster, F in Brazil, the relationship is clearly negative. Thus the evidence from these sets of data is not so clear cut.

The next concluding section includes some further considerations on heterogeneity based on qualitative insights, which help in the interpretation of the findings presented above.

\section{CONCLUSION}

The previous section has shown that the districts are inhabited by many different kinds of firms. With cluster analysis we have classified our sample firms in groups which are internally homogeneous in terms of performance, size, collective efficiency and some other structural features. Within each of the analyzed districts there are several of these groups, which are internally homogeneous but different among themselves, implying therefore a clear internal heterogeneity within districts. This concluding section tries to explain why these heterogeneities occur, and why they differ where they do.

The first point to make is that in a growing industry one should expect heterogeneity. But the industrial district literature does not prepare us for this. To be more precise, what it prepares us for is the deepening division of labour between firms and, as a result, the differentiation of enterprises by process or product. It is however peculiarly quiet on the differentiation by size or by performance. There seems to be an inherent contradiction in the industrial district model. Small firm industrial districts which are successful are unlikely to remain populated by small firms only. Reinvested profits lead to expansion and increasing differentiation by size and performance. While our survey data does not capture the change over time, it confirms considerable differences in performance and size and it also stresses the existence of diverse level of enterprises' local embeddedness.

We know from our previous work that the size differentiation is strongest in the Brazilian case because during the export boom of the 1970s and 1980s the Sinos Valley produced large volumes of standardized shoes for the US market (Schmitz 1995a). The Italian districts also produced for a large export market, but their emphasis was on the European market and differentiated quality production explaining to some extent why size differentiation was lower (Rabellotti 1997). In the data analyzed in section 3, size does not however emerge as one of the main factors in the Brazilian case presumably because, at the time of data collection, the industry was restructuring, shifting in an Italian direction. Perhaps this is why size was not as systematically linked to other variables as one would have expected ${ }^{12}$. While the picture is messy, two observations are worth recording: first, the degree and type of heterogeneity is 
shaped by the size and type of the market; second, the contours of the heterogeneity change over time.

A question which arises from observing these cases is whether large firms contribute to and draw on the district's collective resources as much as small or medium sized firms. The indications are mixed. In the Brazilian case, there was a clear correlation between size and collective efficiency indicators. However, as noted before, some of the largest enterprises (with over 1,000 workers) were not represented in the sample. Six of them have integrated vertically and thus reduced their input into dependence on the district (Schmitz 1995a). Similarly, in the Italian case there are some large firms which seem removed from the district and indifferent to its collective effect (see section 3). And in the Mexican case we noted the indifference of large firms to institutionalized cooperation.

There are, however, limitations to the statistical results of section 3. These limitations lie not so much in the method as in the way the data was collected. As noted before, the surveys were not designed for examining the internal heterogeneity of the districts. If one were to carry out a survey focused on this question which would be the most important categories? In analysis concerned with collective efficiency a critical distinction would be between leaders and followers or between dynamic enterprises and those which merely reproduce themselves. In order to explain why, let us recall that collective efficiency is the competitive advantage derived from external economies and joint action. For dynamic external economies to arise someone has to innovate. For joint action to emerge someone has to take the lead.

Can one tell from our research in Italy, Brazil and Mexico who the critical actors are? Only if we piece together quantitative and qualitative information and even then the answers are preliminary. Perhaps the clearest finding across all three countries is that the smallest enterprises contribute least and tend to free ride. They compete by taking advantage of the "free" external economies and are least involved in joint action. This is not to say that they are all dysfunctional. On the contrary, the districts are constantly revived by new entrepreneurs emerging from below. Clustering facilitates entry and growing in small steps (Schmitz 1997). In the Mexican and Italian cases, medium sized enterprises tended to be the most dynamic in terms of generating external economies and engaging in vertical or horizontal cooperation. In the Brazilian case, both medium and some large enterprises seem to be driving the collective efficiency forward.

To conclude, this paper has presented some tentative conclusions on the internal heterogeneity of districts, based on empirical material which was not collected for this purpose. As research on industrial districts enters a more mature phase, exploring this internal heterogeneity further seems a critical next step. The danger is that it could develop into an inward-looking enterprise of interest only to specialists in this field. However, this need not happen. If further research concentrates on those internal categories which help to understand 
growth or decline then it would be of great interest to the large constituency concerned with industrial development. 


\section{Appendix}

The statistical analysis is based on the results of three surveys carried out in Italy, Brazil and Mexico adopting a very similar questionnaire for samples of randomly selected firms. The sample stratified by size comprises 50 enterprises in Italy, 54 Brazil and 51 in Mexico. The primary survey data was complemented with secondary data as well as with open-ended interviews with key informers, such as sector experts, representatives of business associations and institutions supporting the sector, as well as suppliers and buyers.

The remainder of this appendix details the number of questionnaire respondents by size and countries and lists the variables included in the statistical analysis (3.1).

The sample, number of firms by size

\begin{tabular}{|c|c|c|c|c|}
\hline Country & $<50$ employees & $51-100$ employees & $>100$ employees & Total firms \\
\hline Italy & 24 & 15 & 11 & 50 \\
\hline Brazil & 23 & 12 & 19 & 54 \\
\hline Mexico & 17 & 14 & 20 & 51 \\
\hline
\end{tabular}

\section{Variables selected: Italy}

B1 number of employees

B1012 availability of skilled labor ( $0=$ low; $1=$ high)

B25 \% of products exported

B612 trend of employment ( $1=$ increased; $0=$ remained the same or decreased)

D3 \% of upper stitching put out to other enterprises

F112 technological level (1=good or very good; $0=$ low)

G142 forms of commercialization other than sale representatives (1=yes; $0=$ no)

G31 segment of market (1=high or medium high; $0=$ low)

H21 equity shares in local firms ( $1=$ yes; $0=$ no)

H41 non-equity agreements with local firms (1=yes; $0=$ no)

H612 informal relationships within the districts $(0=$ never; $1=$ occasionally or frequently)

L21 use of the services of the entrepreneurial association $(1=>1 ; 0=\leq 1)$

M11 investments in technology ( $1=$ yes; $0=$ no $)$

M15 investments in commercialization $(1=$ yes; $0=$ no)

M18 investments in other sectors (1=yes; $0=$ no) 


\section{Variables selected: Brazil}

Q21 year in which the firm was established

Q31 number of employees

Q51B trend of production (1=increased; 0= remained the same or decreased)

Q53A \% of exported sales

Q611A1 investments in capacity expansion within the Sinos Valley (1=large amount; $2=$ small amount; $3=$ nil)

Q73C subcontractors lend machines (1=frequently; 2=occasionally; 3=never)

Q92A suppliers offer assistance with problems arising from products $(1=\mathrm{yes} ; 2=\mathrm{no})$

Q101C sales through and independent sale representative $(0=0 ; 1=\leq 25 \% ; 2=26 \%-50 \% ; 3=51 \%$ $74 \% ; 4=\geq 75 \%)$

Q71H1 $\%$ of upper stitching put out to other enterprises $(0=<50 \% ; 1=\geq 50 \%)$

Q161A contacts with the training center $(0=$ no contact; $1=$ occasional or frequent contact $)$

Q161B contacts with the technology center $(0=$ no contact; $1=$ occasional or frequent contact $)$

\section{Variables selected: Mexico}

B1 number of employees

C3512 technological level ( $1=$ good or very good; $0=$ low)

D16 \% of products sold by agents

D7812 original design $(1=$ yes; $0=$ no $)$

DIII1 high segment of market $(1=$ yes; $0=$ no $)$

F1 equity shares in local firms $(1=$ yes; $0=$ no $)$

G1 informal relationships within the districts $(0=$ never; $1=$ occasionally or frequently)

G131 use of services of the entrepreneurial association $(1=>1 ; 0=\leq 1)$

H55 investments in commercialization $(1=$ yes; $0=$ no)

H56 investments in technical training ( $1=$ yes; $0=$ no)

H57 investments in managerial training ( $1=\mathrm{yes} ; 0=$ no)

H76 access to information as a competitive advantage of the firm ( $1=$ yes; $0=$ no)

H78 institutional assistance as a competitive advantage of the firm $(1=$ yes; $0=$ no $)$

H7A product quality as a competitive advantage of the firm ( $1=$ yes; $0=$ no) 


\section{Notes}

1 Although this paper is the result of joint work, Roberta Rabellotti wrote sections 2.1, 2.3, 3 and Hubert Schmitz wrote sections 1, 2.2, 2.4 and 4. Valuable comments on a previous draft were provided by Khalid Nadvi.

2 For a brief presentation of the methodology adopted in the surveys see the Appendix.

3 In the literature on industrial districts the term cluster has been commonly used to refer to a spatial agglomeration of specialized enterprises. Here, instead, cluster is a group of homogeneous firms resulting from the application of cluster analysis to a sub-set of the survey data. In this paper therefore, the term cluster is used in the statistical sense; several clusters can be found in what, in our previous work, we have sometimes defined as the Italian, Brazilian or Mexican clusters.

4 Formally, principal factors are inferred from the original variables and are estimated as linear combinations of them. While all the original variables contribute to a generic factor $F_{j}$, hopefully only a subset of them characterizes that factor, as indicated by their large coefficients (see Tables 3,5 and 7). For each set of variables several factors can be derived provided that factors are not correlated between each other; i.e. principal factors are orthogonal and therefore do not contain overlapping information (each factor explains a specific amount of sample variability). Factors can be ranked in decreasing order, according to the amount of the sample variance they explain (for instance, in the Italian sample the first factor explains 33 per cent of the total sample variance, the second factor 30 per cent and the third 24 per cent). The larger the number of factors selected, the larger the amount of variance explained but the less concise is the information provided by the factor analysis.

5 Table 3 (as well as Table 5 and 7) represents the rotated matrix of factor loadings, which are the weights used to express factors as linear combinations of the standardized variables: factors with large coefficients (in absolute value) for a variable are closely related to that variable. The matrix of factor loadings is transformed - by rotating factors axes - to obtain a rotated matrix easier to interpret than the original one. Rotation redistributes the explained variance for the individual factors. The method for rotation adopted in our analysis is varimax, which attempts to minimize the number of variables that have high loadings on a factor.

6 Cluster analysis operates in the following way: initially $\mathrm{n}$ clusters - each made up of one element of the population - are created; then a new partition is built up by minimizing the distance between clusters and aggregating the nearest groups in a new one, thus obtaining $n-1$ clusters; the procedure is iterated until all the $n$ original objects are assembled in one cluster.

A critical decision is then to decide how many clusters to choose. This can be done by cutting the dendogram (which describes the grouping dynamics) above the low aggregations (which bring together the elements that are very close to each other) and under the high aggregations (which lump together all the groups in the population).

7 The cluster analysis was run for all the factors identified in the three samples, but here we only present the most interesting clusters from an interpretative point of view; the other clusters do not add very much to the results discussed in this section.

8 Note that four enterprises of the original sample do not belong to any cluster, due to the presence of some missing values.

9 For reasons of brevity, the paper does not present all the details about the characterization of each cluster, but these results are available on request from the authors.

10 Heterogeneity depending on size is also confirmed by correspondence analysis carried out on the Italian and Mexican samples (Rabellotti 1997a).

11 The testing of this hypothesis will be attempted with the results of a new sample survey carried out in the Mexican, Brazilian, Indian and Pakistani districts. This research is ongoing.

12 A further possible - but only partial - explanation is that six very large vertically integrated firms were not represented in the Brazilian sample. 


\section{Bibliography}

ABAEX, 1992, Brazilian Footwear 92, Novo Hamburgo: Associação Brasileira dos Agentes de Exportação de Calçados e Afins.

ANAC, 1996, 'Industria dell'accessorio e del componente', ANAC, Milan: mimeo.

ANCI, 1996, 'L'industria calzaturiera Italiana', ANCI, Milan: mimeo.

ASSOMAC, 1996, 'Rapporto Congiunturale', ASSOMAC, Vigevano: mimeo.

CANAICAL, 1995, 'Perfil de la Industria del Calzado', Camaras de la Industria del Calzado, Mexico City: mimeo.

Everitt, B.S., 1983, 'Cluster Analysis', in McKay, D. and Schofield, N., Whiteley, P., eds, Data Analysis and the Social Sciences, London: Frances Pinter.

Gaibisso, A.M., ed., 1992, Struttura e competitività del settore calzaturiero in Italia, Milan: Franco Angeli.

Kim, J. and Mueller, C., 1978, Introduction to Factor Analysis, Beverly Hills and London: Sage University Press.

Knorringa P., 1996, Economics of Collaboration: Indian Shoemakers between Market and Hierarchy, New Dehli and London: Sage.

Nadvi K., 1996, Small Firm Industrial Districts in Pakistan, D.Phil. Thesis, Institute of Development Studies, University of Sussex: Brighton.

Nadvi K., Schmitz H., 1994, "Industrial Clusters in less Developed Countries: Review of Experiences and Research Agenda", IDS Discussion Paper, no. 339, Institute of Development Studies: Brighton.

Rabellotti, R., 1995, 'Is there an 'industrial district Model'? Footwear districts in Italy and Mexico compared', World Development, Vol 23 No 1 January: 29-41.

Rabellotti, R., 1997a, External Economies and Cooperation in Industrial Districts: A Comparison of Italy and Mexico, London: Macmillan.

Rabellotti, R., 1997b, "Devaluation bonanza or something more? Increasing collective efficiency behind the recovery of the Mexican footwear clusters", paper presented at the Collective Efficieny Workshop, Institute of Development Studies, Brighton: 15-16th April.

Schmitz, H., 1995a, 'Small shoemakers and Fordist giants: tale of a supercluster', World Development, Vol 23 No 1 January: 9-28.

Schmitz, H., 1995b, 'Collective efficiency: growth path for small-scale industry', Journal of Development Studies, Vol 31 No 4 April: 529-566. 
Schmitz, H., 1997, 'Collective Efficiency and Increasing Returns', Working Paper No 50, Brighton: Institute of Development Studies, University of Sussex.

UNIC, 1995, 'L'industria conciaria italiana nel 1994', UNIC, Milan: mimeo. 